\title{
O guardador de segredos, Davi Arrigucci Jr.
}

$\bigcup^{S}$ ENSAIOS reunidos nesse volume distribuem-se em três grupos: o primeiro é dedicado à poesia, o segundo à prosa de ficção, e o terceiro volta-se para a crítica. No final, de sobejo, um apêndice "extra" sobre cinema.

O próprio título antecipa o método desse arguto leitor: seu percurso de leitura irá na direção de evidenciar o enigma irresolúvel do símbolo literário. Andar à volta do mistério para circunscrevê-lo, possibilitando que enxerguemos com clareza seus prismas, e assim intensificar o fascínio, constitui o alvo do trajeto, cujo âmbito de escavação aumenta e se aprofunda na proporção da dificuldade.

Em cada novo enfrentamento com diferentes obras literárias, Arrigucci colhe o "pormenor significativo", ou os traços evidentes do estilo de um autor, tendo já palmilhado inúmeras vezes todo o diâmetro de sua produção, e convivido longa e atentamente com a paisagem histórica e cultural que o escritor frequentou, embebendo-se de seu ambiente, para então ir direto ao ponto de ignição - aspecto de qualidade que mais sobressai nesse livro tão variado em seus objetos quanto coeso em sua forma de desdobrá-los ao nosso olhar.

Esse é o tempo de madureza do crítico, que foi adensando sua capacidade para a apreensão do essencial, com apurado "senso da forma". Abre cada um dos mais de vinte ensaios do livro com o anúncio de uma questão decisiva, e guia-nos para o coração das obras que analisa com um amplexo justo que, sem afrouxar nem apertar demais, não deixa nada de fora nem estreita o que se propôs a examinar.
Na primeira parte, elege, a partir de leituras particularizadas, aspectos centrais da poesia brasileira moderna, imitando "o modo de ser da coisa imitada até o seu extremo" e entreabrindo "a margem silenciosa do indizível" para o leitor pressentir sua força expressiva, lastreada pelo enlace entre som e imagem.

Em relação a cada poeta apresentado, surpreende um movimento axial que o caracteriza. Em Drummond, a densidade da reflexão e a dificuldade mentada para atingir o alvo na linguagem, como questão constitutiva; em Cabral, a elaboração consciente da construção paralela ao esforço para atingir a coisa a ser representada; em Gullar, a forma como “o social lateja no mais íntimo de sua linguagem” quando o homem comum torna-se o centro de suas inquietações sobre o destino histórico do presente; em Cecília, o incessante "interrogar-se, em meio à fugacidade de tudo, sobre o sentido de sua recorrente canção".

Se Davi Arrigucci divisa novos ângulos para a interpretação da obra de poetas consagrados que foram contemplados com sólida fortuna crítica, mais acera o gume quando se propõe a penetrar em territórios pouco consolidados, para os quais precisará estabelecer balizas. Quando o desafio se torna maior, então seus acertos são ainda mais evidentes, como ao mergulhar na leitura cerrada de um poeta em estado selvagem, como Roberto Piva, desdobrando considerações críticas em dois ensaios complementares. Procura assimilar sua poética, desvendando as alucinações inspiradas e o ritmo do transe, na perambulação pela cidade, 
que tanto revelam de nossa modernização caótica.

O texto sobre Sebastião Uchoa Leite, que dá nome ao livro, publicado anteriormente como resenha no jornal, já se tornou a pedra de toque para a compreensão desse poeta esquivo. A atitude de recusa e ataque, a desconfiança irônica em relação a tudo e a si próprio firmam-se como ponto de partida para a percepção matizada de Arrigucci acerca dos movimentos de espreita que traduzem tanto o desejo de isolamento quanto uma forma disfarçada de solidariedade.

Em relação ao romance, ao comentar O quinze, de Raquel de Queiróz, reflete sobre a combinação tão particular de tradição oral e forma moderna, observando como a voz narrativa procura contar sua estória por dentro, adequando perfeitamente o estilo da linguagem e a matéria exposta, ao aproximar a paisagem ressecada do sertão da subjetividade da protagonista, que se estiola em resignada solidão naquele mundo hostil.

Ainda no registro do sertão, desenvolve leitura notável dos contos do contemporâneo Ronaldo Correia de Brito, o que participa da proposta desse livro, que mescla leituras de textos canônicos com outros que ainda não receberam os lauréis da crítica.

Com galhardia, Davi Arrigucci enfrenta o romance brasileiro mais complexo do século XX, retomando ideias por ele desenvolvidas alhures sobre as diversas vertentes narrativas que se cruzam em Grande sertão: veredas: o aspecto épico entroncado nos causos de origem oral, a combinatória de arcaico e moderno, a necessidade do protagonista de compreender e dar forma à sua história de vida recontando-a. As relações tão sutis entre literatura e sociedade numa região específica, num tempo que se prolonga, comparecem problematizadas nesta e em todas as suas leituras.

De modo análogo, ao tratar de Os ratos, de Dyonélio Machado, o crítico encarece a associação entre o roedor furtivo mas tenaz, e o personagem desesperado que ronda a cidade à cata de migalhas, como os pequenos funcionários da literatura russa, circulando obsessivamente para conseguir sobreviver.

Ampliando seus territórios de investigação, abre espaço para escritores latino-americanos: o pouco lido Felisberto Hernandez - cavalo perdido, extravagante, que Davi recolhe -, o fictício Bustos Domecq ("heterônimo" criado em colaboração por Jorge Luiz Borges e Bioy Casares durante sua longa amizade literária cuja voz pode ser especialmente sarcástica em relação aos males da sociedade argentina), e finalmente Juan Rulfo, no qual percebe afinidades com Guimarães Rosa na forma de narrar orgânica e contígua à experiência do pobre, revelando o vínculo profundo com a sua região, que é vista a partir da perspectiva dos oprimidos pelas violentas tempestades históricas.

Os ensaios finais, em homenagem às obras de Gilda de Mello e Souza e de Marlise Meyer, assim como as entrevistas (uma acerca da influência formadora de Antonio Candido e outra a respeito de aproximações e diferenças de sua forma de leitura relativamente à psicanálise) acabam por converter-se em comentários sobre seu próprio método de abordagem da obra literária. Justamente o que Davi aprecia nos críticos que estuda é aquilo que melhor o caracteriza. Em Gilda, destaca o fino sentido de proporção, que sabiamente integra o detalhe significativo ao todo da obra, aderindo empaticamen- 


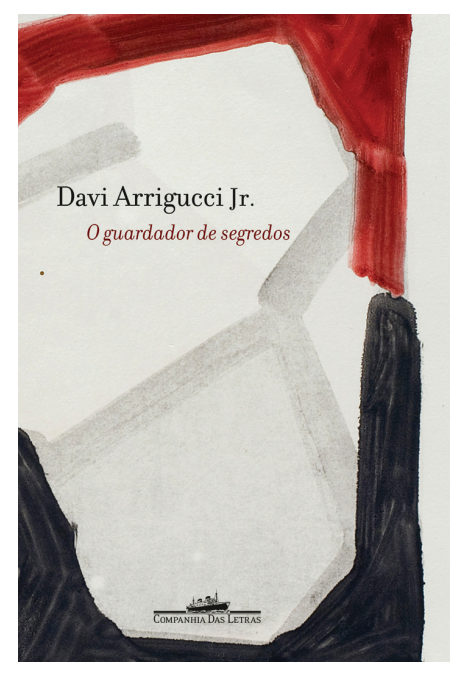

ARRIGUCI Jr., Davi. O guardador

de segredos. São Paulo: Cia. das Letras, 2010.

te ao objeto de estudo sem com isso perder nem o sentido analítico nem a graça da intuição precisa. Em Marlise Meyer admira a liberdade da "imaginação andarilha" que mescla cultura popular e erudita em seus estudos, aproximando a composição rocambolesca do romance de folhetim da estrutura dos faits divers nos jornais.

Revendo sua formação teórica reconhece, na estilística e, depois, no encontro com a obra de Antonio Candido as influências modelares que lhe permitiram adquirir uma "estratégia maleável e móvel de abordagem dos textos", que superasse tanto o formalismo imanentista quanto o reducionismo sociológico. $\mathrm{O}$ estudo consistente e aprofundado da forma estética constitui sua porta de entrada para inferir os aspectos sociais da obra, que os transfigura em busca de significados simbólicos para o real. De novo, o pormenor que se prolonga e tantas vezes reaparece é o escolho do concreto que não deve ser ignorado, nem passa- do ao largo. A investigação dos sentidos do texto, que se inicia nos comentários preliminares, visando ao entendimento dos termos e referências, e caminha na direção da interpretação, se tem algo de circular - uma vez que parte já de uma primeira configuração do sentido do todo - nada tem de fechado, pois deveria manter sempre em aberto a ambiguidade fundamental da literatura.

Assim age ao deslindar as articulações das sequências de eventos frenéticos num filme de Hitchcock, no qual os nós da cadeia de eventos estão amarrados para criar um clima de suspense e, às vezes, terror. Em cada detalhe se deposita alguma secreta ironia ou inversão de expectativa, enquanto o espectador é conduzido aos trambolhões da dúvida metafísica à vida mais comum e vice-versa. Desde um alfinete até uma gravata... todos os objetos servem a um sentido oculto.

Uma das mensagens centrais do livro é a ideia reiterada de que o estético manifesta-se como "claro enigma”, permanecendo aberto em seu mistério de coisa sem fim. Se a poesia condensa a linguagem enquanto a narrativa a desdobra, ambas perpetuam, em seu movimento, a demanda que nunca se esgota.

A escrita do crítico costura as teorias por dentro, sem precisar nomeá-las a toda hora, uma vez que se tornaram inerentes ao seu olhar, nelas de tal modo embebido que parecem conaturais. Espelha-se na advertência de Benjamin, que recomendava ao leitor um esforço para limpar as cinzas depositadas pelo tempo na obra artística para avivar as chamas que em seu fundo cintilam. E, lembrando Damaso Alonso, intenta "dar à caça alcance" por meio do ousado salto da intuição empática, quando o sujeito abraça o seu objeto e quer abarcá-lo, completo, 
imitando, nesse impulso, o método analógico da arte. Ao mesmo tempo que se projeta afetivamente para o interior do texto, procura distinguir cada uma das partes que o constitui, com "atenção flutuante", para chegar a uma interpretação coerente do todo, sempre respeitando a inesgotabilidade da obra literária.

Mas, além de toda explicitação de um caminho analítico-interpretativo, o mais relevante é o apuro tão pessoal e irrepetível de cada leitura, cujo resultado não provém de nenhuma especial receita, e sim da mão do crítico, no qual convivem a escuta muito fina e o vigor da configuração imaginativa, possibilitando esses marcantes estudos e variações à volta de tantos autores contemplados, aos quais os ensaios conferem viva voz.

Viviana Bosi é professora do Departamento de Teoria Literária e Literatura Comparada da Faculdade de Filosofia Letras e Ciências Humanas da Universidade de São Paulo. @-vivianab@usp.br 